Document downloaded from:

http://hdl.handle.net/10251/39861

This paper must be cited as:

María-Antonia Serrano; Boscá Berga, JV. (2013). Selection of cloudless sky conditions by applying solar globalultraviolet irradiance measurements. Atmospheric Research. 132133:291-298. doi:10.1016/j.atmosres.2013.05.020.

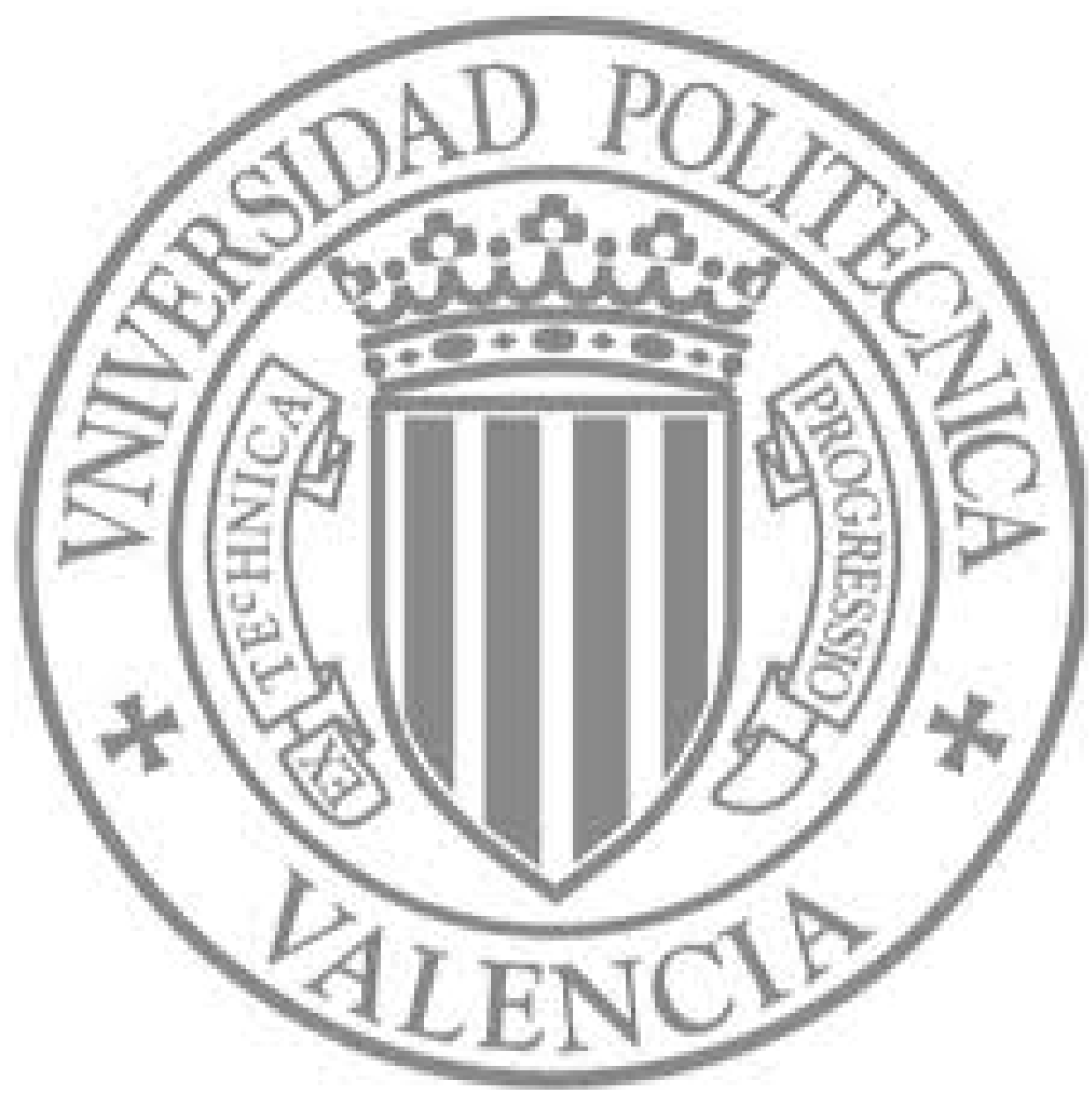

The final publication is available at

http://dx.doi.org/10.1016/j.atmosres.2013.05.020

Copyright Elsevier 


\title{
Selection of Cloudless Sky Conditions by Applying Solar Global Ultraviolet Irradiance Measurements
}

\author{
María-Antonia Serrano, ${ }^{\mathrm{a}^{*}}$ José V. Boscà ${ }^{\mathrm{b}}$
}

${ }^{a}$ Instituto de Ingeniería Energética, Universitat Politècnica de València, Valencia, Spain

buniversitat Politècnica de València, Valencia, España

\section{ABSTRACT}

Taking advantage of UV (290295-385 nm) irradiance measurements is one of the objectives of this paper. A new index termed $\mathrm{k}_{\mathrm{t}}$ ' is established for this band. This new index works as a 'zenith angle independent clearness index' for band measurements and has similar applications to those of $\mathrm{k}_{\mathrm{t}}$ ' for broadband measurements. The new index may be applied to identify cloudless instants from UV band measurements. Both indexes were correlated throughout the period 1998-2004 with a $\mathrm{R}^{2}$ of 0.85 . A selection criterion of $\mathrm{k}_{\mathrm{t}}$ " $\mathrm{uV}>1.1$ classified cloudless sky conditions with a probability of $95 \%$ in comparison with a selection that two criteria-applying broadband measurements would make. This index may be of interest for classifying cloudless sky conditions when only UV band measurements are available. An estimation method from the literature was applied to the period 1998-2004. This method was previously validated for the UV band with a measurement campaign made in Valencia (Spain) in the summer season.

Keywords: clearness index; cloudless conditions; estimation method; ultraviolet solar irradiance.

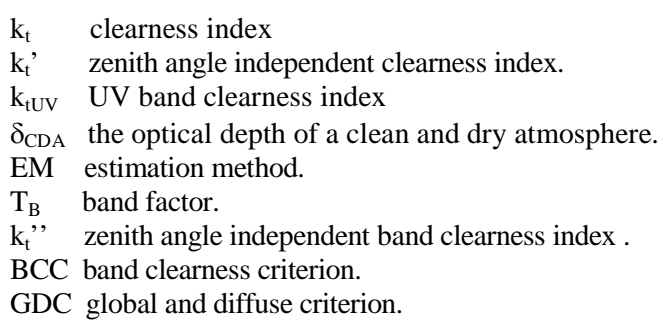

* Corresponding author:

Instituto de Ingeniería Energética, Universitat Politècnica de València, Camino de Vera s/n 46022 Valencia, España. Phone: +34 963877007 ext 75308.

E-mail address: mserranj@fis.upv.es (María-Antonia Serrano). 


\section{Introduction}

Spectroradiometers and photo-detectors are commonly used to measure solar radiation. A few seconds are enough for the measuring instrument to explore the whole solar spectrum and provide a complete set of irradiances with precise wavelength ranges of nanometres. However, in the second half of the twentieth century spectral measurements were not so common and most meteorological and radiation stations recorded irradiance measurements from the whole spectrum, namely broadband irradiance, and also from bands of the spectrum of special interest.

Radiation of bands of the solar spectrum are measured and analyzed for many reasons. Researchers focus their interests in different bands of the Ultraviolet Spectrum such as the bands UV-A, UV-B, UV-C, whose ranges and nomenclature were standardised by the Commision Internationale de l'Eclairage (Barth et al. 1999), mainly due to the interest to know its influences over the animal life and plants and also its incidence on the aging of materials and objects.

These bands of the ultraviolet spectrum are measured and analyzed by many researchers. Among many of them, we could highlight some works, such as that of Kudish and Evseev (2012) who parameterized the three solar UV-B radiant components (direct, global and diffuse) as a function of relative optical air mass, and also they determined the UV-B optical depth by parameterizations applying similar procedures which are used at this work. Jacovides et al. (2012) also managed measurements of global and diffuse (broadband, UV-B and UV-A) irradiances to study their components and relations with the broadband radiant fluxes, and they also applied measurement techniques, similar to ours, such as applying a disk to shadow the instrument to measure diffuse irradiance. Regarding the UV band, Parisi and Kimlin (1999) analyzed the dependence of the irradiance of this band according to the orientation of the object. In other study, Parisi et al. (2000) compared the diffuse erythemal UV irradiance in tree shade with the corresponding in full sun. Turnburn et al. (2005) performed spectral UV irradiance measurements for six specific shade environments in full sun and in the shade, to investigate the biologically effective UV irradiance for pre-Vitamin D3 production.

A band alike UV-A is that of wavelength range 290295-385 nm. There are available large databases with irradiance measurements of that band in Spain since it has been measured for more than 20 years by stations of the Spanish Meteorological Agency and by groups of researchers such as ours at the Polytechnic University of Valencia. That is why the interest of this paper is focussed on the band UV (290295-385 nm), which hereafter will be referred to as UV band, and its irradiance being measured beneath the atmosphere of Valencia, Spain.

When the measurements managed were broadband irradiance, to make a selection of cloudless conditions was very well solved. Below there are summarised two broadband methods to do that. Broadband measurements also have served to classify band measurements when they were available. But some techniques and methods are missing to classify band measurements when they are the only available.

The objective of this work is to provide a method to select cloudless instants when the available measurements are direct normal UV band irradiance, or, failing that, UV global horizontal irradiance. To reach that objective a new index, $\mathrm{k}$ ", , for the band UV will be defined. This new band index will be applied to identify conditions of cloudless sky from the UV band irradiance at the instant when the 
measurement was taken. A new criterion to identify cloudless conditions from UV band irradiance measurements based on the new band index was established.

To determine that index a parameterisation of the optical vertical thickness under a clean and dry atmosphere and the determination of a Band Factor were previously needed. Therefore, these parameters were cited and summarised from the literature, and validated to be applied to the UV band. Also, an Estimation Method (EM), with the purpose to yield direct normal band irradiance from global horizontal, was previously validated for the band UV, and then applied, to make a better use of our databases.

Finally, the new band criterion for cloudless skies was validated by comparisons, in a period of two years reserved for this purpose, with the results performed by two other classification methods based on broadband measurements.

\section{Data Utilized and Methodology}

Two solar radiation databases were applied in this study. The first database contained measurements from 1996 to 2004 made at the Universitat Politècnica de València (UPV) by the group of researchers on Solar Radiation of this University, which the authors were members, and was led by Professor Dr. Javier Cañada This group is integrated in the Solar Radiation Group of Valencia (SRGV), Spain. The second database consists of measurements made by the authors in a special measurement campaign, also at the UPV, held in June and July 2006. The UPV coordinates are $0^{\circ} 20^{\prime} 18^{\prime \prime} \mathrm{W}-39^{\circ} 28^{\prime} 49^{\prime \prime} \mathrm{N}$ and the measurements were made on a flat roof at about $15 \mathrm{~m}$ above the sea level.

\subsection{SRGV and Experimental Campaign Databases}

The database contains measurements taken every half hour in all atmospheric conditions during the period between 1996 and 2004 and includes a total of 50,672 registered instants - with the only exception of data missed due to momentary breakdowns or errors.

The database contains the following variables:

1 - Broadband global and diffuse horizontal irradiances, measured with two pyranometers Eppley model 8-48 with a spectral range of $285-2800 \mathrm{~nm}$. The second pyranometer was equipped with a $7.6 \mathrm{~cm}$ wide shadow-band with a radius of $31.70 \mathrm{~cm}$ for the diffuse irradiance. The diffuse irradiance measurements were corrected using Drummond's formula, as summarised in Iqbal (1983), although the use of this isotropic correction can lead to some error, see for example a study by Batlles et al. (1995) made in another region of Spain. The pyranometers had a class 1 precision following the specifications of the World Meteorology Organization (WMO), and its cosine response is within $\pm 2 \%$ from 0 to $70^{\circ}$ zenith angle and $\pm 5 \%$ for $70-80^{\circ}$ zenith angles. The field measurement uncertainty of the pyranometers is considered to be below $5 \%$, according to the manufacturer.

2 - UV band global horizontal irradiance was measured with an Eppley TUVR pyranometer, placed on a horizontal surface, with a spectral range, given by the manufacturer, of 290295-385 nm. Its cosine response is $\pm 3.5 \%$ from 0 to $70^{\circ}$ zenith angle, and its linearity is $\pm 2 \%$ over the normal range of operation. 
Under these conditions, Mehos et al. (1992) and Riordan et al. (1990) have established that errors associated with the experimental data are conservatively estimated at $15 \%$, which is not in accordance with the expectation of the manufacturer (5\%).

The SRGV carried out periodic calibrations of the above instruments using procedures recommended by the manufacturers, as can be seen in Cañada et al (2000 and Gañada et al. 2003). The broadband pyranometers were compared yearly against a reference Eppley PSP especially kept for calibrations, and the calibration constant had remained practically constant. The TUVR pyranometer was calibrated by the manufacturers at the end of 1995 and afterwards was calibrated yearly in comparison with the measurements of a spectroradiometer LICOR-1800, and a decrease in the calibration constant of $12 \%$ in 3 years was confirmed. In February of 1999, the manufacturer calibrated it again and a decrease in the calibration constant of a yearly $2.5 \%$ per year was observed in the calibration constant. The most recent calibration of this instrument was made in May 2002.

A measurement campaign was carried out in June and July, 2006, with the objective of checking the EM. Hourly measurements of global and diffuse horizontal irradiance of the UV band were performed taking advantage of an automatic system that registered instrument signals every minute.

The measurements were the following:

1: Global horizontal broadband irradiance was measured with a Kipp \& Zonen CM11 pyranometer.

2: Diffuse horizontal broadband irradiance with a Kipp \& Zonen CM11 pyranometer equipped with a shadow band $7.7 \mathrm{~cm}$ wide and with a radius of $32.25 \mathrm{~cm}$. Diffuse data was corrected applying Drummond's formula following Iqbal (1983), despite the risk of a small error mentioned above. Both Kipp \& Zonen instruments have a spectral range of 285-2800 nm. According to the manufacturer, global and diffuse measurements have an estimated instrumental uncertainity of about 2-3\% (Kratzenberg 2006). The CM-11 was regularly recalibrated by the authors by direct comparison with the mentioned Eppley 848 once it was calibrated with the Eppley PSP, and the most recent comparisons were made in June 2006. It was obtained that temporal degradation of this pyranometer was about a few tenths of a percent per year, and then the calibration factor was changed.

3: Global horizontal irradiance of the UV band measured with the Eppley TUVR instrument mentioned above.

4: Diffuse horizontal irradiance of the UV band was registered two minutes later when the instrument was shadowed using a disk that was specially designed for this purpose. An observer applied the shadow disk and at the same time noted the sky conditions (visibility, cloudless, cloudy). To shade the UV instrument, a black shadow disk with a $15 \mathrm{~cm}$ diameter intercepted the sun's rays at a distance of $45 \mathrm{~cm}$ during four minutes. The automatic registering system takes one measurement per minute, then this enabled the storage of at least three diffuse measurements each time, whose average value was taken as the UV diffuse horizontal irradiance, once it had been corrected due to overshadowing (as explained below). The UV global horizontal irradiance was obtained from the average of the two contiguous measurements at the same instant, and then direct normal irradiance of the band was deduced from diffuse and global irradiancesfigures.

This operation was carried out every hour of true solar time-between 8:00 am and 1:00 pm true solar time, and the observer took note of the exact time when the database stored the modified measurements 
and he was also the responsible for recording the presence or absence of clouds. The criterion followed by the observer was to classify as cloudless conditions only when the sky is free of clouds and always a sharp shadow on the instrument can be observed.

A similar procedure was applied by Parisi and Kimlin (1999) to determine UV horizontal diffuse irradiance, shadowing the instrument by placing an occluding disk of $10 \mathrm{~cm}$ diameter approximately 20 $\mathrm{cm}$ between the aperture of the integrating sphere and the sun direction (standard ratio 1:2). Other researchers (Jacovides et al. 2009, Jacovides et al. 2012) also have applied the method to shade with a disk with the standard ratio 1:10. We believe that the 1:3 ratio utilized in our campaign was necessary to ensure a fully shade and that's why we applied this ratio in our measurement campaign in 2006, July (Serrano 2007, Serrano and Boscà. 2011).

\section{Table 1}

Data corresponding to cloudless sky of UV global and diffuse irradiance and number of measurements per day:

\begin{tabular}{lll}
\hline Month & Days with measurements & Respective number of measurements/day \\
\hline June & $8,9,13,14,16,20-24,26,29,30$ & $3,1,5,1,1,3,3,5,5,2,4,4,6$ \\
July & $5,10,11,13,14,17,19-21,24,26,28,31$ & $5,6,1,5,3,6,4,6,5,4,7,7,7$ \\
Total & 26 & 109 \\
\hline
\end{tabular}

The measurement campaign database, containing more cloudlessclear instants than cloudy instants, held 31 effective days with 163 total measurements. Measurements of global and diffuse horizontal irradiance of the band studied for this work were obtained, and from these UV direct normal irradiance was calculated.

Measurements of totally and partially cloudy instants were excluded from the database by the observer, resulting in a total of 109 available measurements for the UV band as shown in Table 1.

The use of the shadow disk makes it necessary to correct the diffuse measurement since this procedure eliminates direct normal irradiance as well as part of the diffuse irradiance. To correct the geometric effect of the shadow disk on the diffuse irradiance data we considered the model mentioned in Iqbal (1983) and given by the equation:

$$
C_{D}=\frac{1}{\left[1-\frac{S / r^{2}}{2 \pi}\right]}
$$

Where $S$ is the surface of the shadow disk and $r$ the height at which it is placed. $S / r^{2}$ is the solid angle covered by the shadow disk which equals 0.0913 strad. This value divided by $2 \pi$ represents 0.014527 of the total celestial vault. Therefore, the $C_{D}$ factor is, in this occasion, 1.0147 . 


\subsection{Methodology and Definitions}

The dimensionless parameter clearness index, $\mathrm{k}_{\mathrm{t}}$, was defined as the ratio of global horizontal irradiance at the Earth's surface over extraterrestrial horizontal irradiance and it describes insolation conditions at a given point in time when only global broadband irradiance is known (Black et al. 1954).

This index was also determined from hourly and daily integrated values of broadband irradiance and it was applied to analyse characteristic distributions of direct, diffuse and total solar radiation in different locations for various categories of days of several degrees of cloudiness (Liu and Jordan1960), and also it was widely used to model other indexes of direct and diffuse radiation in clear or cloudy sky conditions such as Collares-Pereira and Rabl (1979), and Boata and Gravila (2012) and others.

The clearness index $k_{t}$ was insufficient to determine if the sky is cloudy or not at the instant when the measurement was taken. To appreciate 'clearness', if it is understood as a condition of a cloud-free sky, other parameters were necessary. A new parameter termed the 'zenith angle independent clearness index', $\mathrm{k}_{\mathrm{t}}$, was established by Perez et al. (1990) as

$k_{t}{ }^{\prime}=\frac{k_{t}}{0.1+1.031 e^{-1.4 /\left(0.9+9.4 / m_{r}\right)}}$

dividing $k_{t}$ by the expression in the denominator of eq. (2), which is a function of relative optical air mass $\left(\mathrm{m}_{\mathrm{r}}\right)$, and then of the zenith angle. The new index $\mathrm{k}_{\mathrm{t}}$ ' represents the fraction of global irradiance divided not by the solar constant, but by an estimation of the current total horizontal irradiance (diffuse and direct) according to the corresponding $\mathrm{m}_{\mathrm{r}}$.

Equation 2 has been developed on the basis of To reach this expression, it was helpful-Kasten's (1980) parameterisation of the optical vertical thickness of a clean and dry atmosphere $\left(\delta_{\mathrm{CDA}}\right)$ versus $\mathrm{m}_{\mathrm{r}}$,

$$
\delta_{C D A}=\left(9.4+0.9 m_{r}\right)^{-1}
$$

This new index allowed Molineaux et al. (1995) to consider to be cloudless conditions when values of $\mathrm{k}_{\mathrm{t}}$ were up to 0.7 . This criterion will be applied in this study to select cloudless conditions from broadband measurements, and it will be referred hereafter as the ' $\mathrm{k}_{\mathrm{t}}$ criterion', and its results will be compared with those of a new criterion based on UV data to be proposed below.

The new criterion based on UV measurements also will be compared with the selection method applied by Boscà et al. (1996), which will be called hereafter Global and Diffuse Criterion (GDC), because global and diffuse horizontal irradiance are the two input data. Threshold values of direct normal irradiance for every instant were determined by applying the broadband Iqbal C Model (Iqbal 1983) in conditions of high turbidity and high water vapour content in the atmosphere. Then, if the current direct normal was less than the threshold value, a cloud coverage was supposed. Previously, maximum values of the Angström turbidity coefficient $\beta$ and precipitable water $\mathrm{w}_{\mathrm{p}}$ in Valencia Spain were obtained. This process is summarised in Boscà et al. (1996) in the section 'Realizsation and treatment of experimental measurements'. 
Other authors opted to use other appropriate broadband criteria, such as Alados-Arboledas et al. (2000), who established for cloudless conditions that $\mathrm{k}_{\mathrm{t}}$ must be greater than a given expression which is a function of the zenith angle, in a similar way that $\mathrm{k}_{\mathrm{t}}$ criterion.

A new index has been introduced in the literature to analyze band measurements that is the equivalent to broadband $\mathrm{k}_{\mathrm{t}}$, but now dividing the global horizontal band irradiance by the solar constant of the band. For the UV band it was called $\mathrm{k}_{\mathrm{tUV}}$, and it was correlated with broadband $\mathrm{k}_{\mathrm{t}}$, UV, and broadband irradiance measurements (Foyo Moreno et al. 1999, Martínez Lozano et al. 1994, Martínez Lozano et al. 1999, Cañada et al. 2000, Cañada et al. 2003, Ogunjobi and Kim 2004, Bo et al. 2010). But it is important to remark that the extraterrestrial solar constant between the wavelengths $290 \underline{295}$ to $385 \mathrm{~nm}$, obtained from the spectrum of Gueymard (2004), reaches a value of $83.802 \underline{80.985} \mathrm{~W} / \mathrm{m}^{2}$.

Again, $\mathrm{k}_{\mathrm{tUV}}$, as it happened $\mathrm{k}_{\mathrm{t}}$ for broadband, was insufficient to determine cloudless conditions, and then, when broadband measurements are unavailable and temporal series of irradiance measurements of the UV band must be managed, a new index is requiredmissed to select cloudless sky conditions, because there are not identifiers based on band measurements.

Then, the aim of this paper is to introduce a new band index, which will be named $\mathrm{k}_{\mathrm{t}}{ }^{\prime} \mathrm{uv}$, to play a similar role to the broadband's $\mathrm{k}_{\mathrm{t}}$ ' by Richard Perez, to find a relationship between UV band irradiance measurements and cloud coverage.

Before establish $\mathrm{k}_{\mathrm{t}}$ "' $\mathrm{uv}$, it was necessary to apply a Band Factor $\mathrm{T}_{\mathrm{B}}$, which was defined by Serrano et al. (2008) representing the number of Clean and Dry Atmospheres needed to produce the same attenuation to the direct normal irradiance of the band than the current atmosphere does. Namely it represents the ratio of the current optical depth for the band to the optical depth in a clean and dry atmosphere, $T_{B}=\delta / \delta_{C D A}$.

$T_{B}$ was established in Serrano et al. (2008) as determined from measurements of direct normal irradiance of the band, $\mathrm{I}_{\mathrm{n}}$.

$T_{B}(U V)=\frac{1}{m_{r} \delta_{C D A}(U V)} \ln \left[\frac{E_{0} I_{0}(U V)}{I_{n}(U V)}\right]$

where $\mathrm{I}_{0}(\mathrm{UV})$ is the $\mathrm{UV}$ extraterrestrial solar constant equals $83.80280 .985 \mathrm{~W} / \mathrm{m}^{2}$, and $\delta_{\mathrm{CDA}}(\mathrm{UV})$ is the optical depth of a clean and dry atmosphere of the UV band, parameterised by Serrano (2007), and Serrano et al. (2008), versus $\mathrm{m}_{\mathrm{r}}$.

The expression $\delta_{\mathrm{CDA}}(\mathrm{UV})$ as a function of $\mathrm{m}_{\mathrm{r}}$ was also necessary to determine series of $\mathrm{T}_{\mathrm{B}}$ in Valencia.

First, to achieve the parameterization $\delta_{\mathrm{CDA}}$ versus $\mathrm{m}_{\mathrm{r}}$, every $\delta_{\mathrm{CDA}}$ was determined integrating the following expression

$\left(\sum_{\lambda_{1}}^{\lambda_{2}} I_{0 \lambda} \Delta \lambda\right) \exp \left(-m_{r} \delta_{C D A}\right)=\sum_{\lambda_{1}}^{\lambda_{2}} I_{0 \lambda}\left\{\exp \left[-m_{r}\left(\delta_{r \lambda}+\delta_{g \lambda}+\delta_{o \lambda}\right)\right]\right\} \Delta \lambda$

along the UV band range, for every given value of $\mathrm{m}_{\mathrm{r}}$ from 1.1 to 10 inby 0.1 steps, and where $\mathrm{I}_{0 \lambda}$ is the extraterrestrial solar spectral irradiance according to Gueymard Gueymard's spectral solar constant irradiance-(Gueymard 2004) and $\delta_{\mathrm{r} \lambda}, \delta_{\mathrm{g} \lambda}$, and $\delta_{\mathrm{o} \lambda}$, are the eorresponding optical depths due to Rayleigh scattering, absorption by uniformly mixed gases, and ozone respectively. For every wavelength, the absorption and scattering coefficients were updated by Gueymard (2004) to determine these optical 
depths. Second, a correlation with all the obtained couples $\left(\mathrm{m}_{\mathrm{r}}, \delta_{\mathrm{CDA}}\right)$ was made, and the resulting expression was

$$
\delta_{\mathrm{CDA}}(\mathrm{UV})=\left(1.095+0.1715 \mathrm{~m}_{\mathrm{r}}-1.944 \mathrm{E}-2 \mathrm{~m}_{\mathrm{r}}^{2}+8.618 \mathrm{E}-4 \mathrm{~m}_{\mathrm{r}}^{3}\right)^{-1}
$$

with a coefficient $\mathrm{R}^{2}=0.9983$ for a confidence interval of $95 \%$.

Determining $T_{B}$ may serve as a way to characterise the state of the atmosphere at the measurement instant, and may be a tool of interest to determine turbidity and clearness levels. Measurements of $I_{n}$ in the band will be necessary to apply Equation (4).

When large databases with direct normal irradiance of a band are unavailable, as is the case in this work, EM, validated in Section 3.1, is applied to determine $\mathrm{T}_{\mathrm{B}}$.

In this section we propose a new index, $\mathrm{k}_{\mathrm{t}}$,", to be a band clearness index, independent of the zenith angle, defined asand which expresses the ratio of direct normal_irradiance in the UV band over the minimun direct normal irradiance in the UV band under cloudless conditions. direct normal irradiance minimum of the UV band that would exist at that moment in a cloudless sky.

The proposed index is determined for all instants of the period 1998-2004 with available measurements of irradiance. This is achieved by the establishment, such as it will be shown in Section 3.2, implementation_of athe threshold value for the UV Band Factor $\left(\mathrm{T}_{\text {Bmax }}\right)$. show in Section 3.2. The EM is also applied for the UV band (validated in Section 3.1).

The $\mathrm{k}_{\mathrm{t}}{ }^{\prime} \mathrm{uv}$ index is obtained with the following expression

$$
k_{t} " U V=\frac{I_{n}(U V)}{I_{n \min }(U V)}
$$

Where $I_{n}(U V)$ corresponds to the experimental values of direct normal irradiance of the UV band, while $\mathrm{I}_{\mathrm{nmin}}(\mathrm{UV})$ is the UV direct normal irradiance minimum for conditions of clear instants. The direct normal irradiance of the UV band from 1998 to 2004 was determined from global horizontal irradiance of the band using the EM. Bouguer's law is applied to determine the direct normal irradiance minimum of the UV band, which corresponds to the denominator of the expression (7).

$$
I_{n}=E_{0} I_{0} \exp \left(-\delta_{C D A} T_{B} m_{r}\right)
$$

by consideringis applied to atmospheric conditions of maximum attenuation, and therefore including the $\mathrm{T}_{\mathrm{Bmax}}$ value and resulting in the following expression

$$
I_{n \min }(U V)=E_{0} I_{0}(U V) \exp \left(-m_{r} \delta_{C D A}(U V) T_{B \max }(U V)\right)
$$

where all variables have been previously defined mentioned. 


\section{Results and Discussion}

\subsection{Proposed Model and Validation}

The EM, described in Serrano et al. (2008) and Serrano and Boscà (2011), is a method to estimate direct normal irradiance of spectral bands from global horizontal measurements for cloudless sky conditions in Valencia. In Serrano and Boscà (2011) the EM was validated for UV-A and PAR bands, and in this section it is validated for the UV band by means of a-using the data set gathered in the previously described measurement campaign, and after applying the cloud screening procedure described aboveonly after the cloudy instants - in accordance with the observer's criterion - were dropped. Table 1 shows the number of cloudless measurements as 109.

In Serrano et al. (2008), the ratio of direct normal over global horizontal irradiance of the UV band (both provided by the Smarts2 model (Gueymard 2003)) for the climatic characteristics of the city of Valencia were parameterised versus the relative optical air mass. The objective of this parameterisation was to obtain an EM to determine UV direct normal irradiance from experimental measurements of UV global horizontal irradiance for every $\mathrm{m}_{\mathrm{r}}$. In the cited reference, the EM was summarized in the section entitled 'A simple method to generate direct normal irradiance from global irradiance of the band' and was proposed for application to the UV-B $(280-315 \mathrm{~nm})$ band and to the UV band. EM was subsequently applied and validated by Serrano and Boscà (2011) for measurements of UV-A (315-400 nm) and PAR (400-700 nm) bands.

The parameterised function of the correlation of $I_{n} / I$ versus $m_{r}$ and its $R^{2}$ coefficient for a confidence level of $95 \%$ is shown in Table 2 , where $I_{n}$ is the direct normal band irradiance and $I$ is the global horizontal band irradiance.

To analyse the deviation of the estimated values of the direct normal irradiance obtained by the EM from the experimental values obtained in the measurement campaign, three different error estimators were used: the root mean square error (RMSE); mean bias error (MBE); and mean absolute bias error (MABE). The first represents the variance of the experimental data versus those obtained by the EM, while the last two estimators provide information on over- or under-estimations in a particular range. We also analysed the linear regression between estimated and measured values and obtained the $\mathrm{R}^{2}$ coefficient. Figure 1 shows the correlation between the experimental direct normal irradiance and the values provided by the EM.

\section{Table 2}

Results of parameterisations of $\mathrm{I}_{\mathrm{n}} / \mathrm{I}$ versus $\mathrm{m}_{\mathrm{r}}$ for Valencia (Spain).

\begin{tabular}{llc} 
Band & $\mathbf{I}_{\mathbf{n}} / \mathbf{I}$ & $\mathbf{R}^{2}$ \\
\hline $\mathrm{UV}$ & $5.477 \mathrm{E}-2+0.8413 \mathrm{~m}_{\mathrm{r}}-0.3674 \mathrm{~m}_{\mathrm{f}}{ }^{2}+5.654 \mathrm{E}-2 \mathrm{~m}_{\mathrm{f}}{ }^{3}-3.040 \mathrm{E}-$ & 0.999 \\
\hline
\end{tabular}


$R M S E=\left[\frac{1}{N} \sum_{i=1}^{N}\left(E_{i}-O_{i}\right)^{2}\right]^{1 / 2}$

$M B E=\frac{1}{N} \sum_{i=1}^{N}\left(E_{i}-O_{i}\right)$

$M A B E=\frac{1}{N} \sum_{i=1}^{N}\left|E_{i}-O_{i}\right|$

The parameterised function ${ }_{2}$ and the $R^{2}$ coefficient, of the of the correlation between the UV direct normal irradiance-values_, provided using applying the-EM, method and the experimental UV direct normal irradiance is shown in Table 3 values and its $R^{2}$ for a confidence level of $95 \%$ is shown in Table 3. . In this table the values of $\mathrm{RMSE}(\%), \operatorname{MBE}(\%)$ and $\operatorname{MABE}(\%)$ values are also shown. These values-are the previous estimators cited above, expressedbut calculated in relative terms regarding the average experimental $\underline{\mathrm{UV}}$ direct normal irradiance $I_{n}$ (aver.), and serve to emphasise the magnitude of the error.

\section{Table 3}

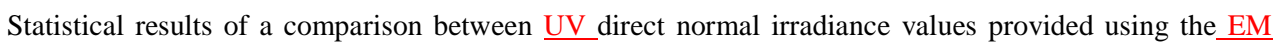
method and the UV experimental values.

\begin{tabular}{|c|c|c|c|c|c|c|}
\hline Band & $\begin{array}{l}I_{n} \text { (aver.) } \\
\left(W / m^{2}\right)\end{array}$ & Fitting equation & $R^{2}$ & $\begin{array}{l}\text { RMSE } \\
(\%)\end{array}$ & $\begin{array}{l}M B E \\
(\%)\end{array}$ & $\begin{array}{l}\text { MABE } \\
\text { (\%) }\end{array}$ \\
\hline UV & 25.73 & $\mathrm{I}_{\mathrm{n}}(\mathrm{UV})$ estimated $=6.849+0.794 \mathrm{I}_{\mathrm{n}}(\mathrm{UV})$ experimental & 0.88 & 8.64 & 6.07 & 7.09 \\
\hline
\end{tabular}

Let us consider that MBE (\%) $>0$ means that the EM tends to overestimate the true UV direct normal irradiance values, whereas MBE $(\%)<0$ corresponds to an underestimation.

According to the values of the MBE (\%) estimator, the model tends to overestimate the direct normal irradiance of the UV band by $6 \%$. The other two error estimators have similar orders of magnitude. The results of the comparisons reveal that the accuracy of EM is good, with RMSE (\%) less than $10 \%$ for the UV band analysed.

Thus, the EM was validated by comparison with the UV direct normal irradiance measurements provided by a campaign of measurements, and so we can determine the direct normal irradiance of this band when the available measurements are of global horizontal band irradiance. Approximate methods to provide direct irradiance from global irradiance have been developed in the literature for broadband measurements, but not for band measurements. The EM can be very helpful in determining direct normal 
band irradiance from the easily available global horizontal band measurements in Valencia (Spain). The EM was applied to the UV global horizontal irradiance measurements for the period 1996-2004 to provide a large database of UV direct normal irradiance, necessary to determine a new index $\mathrm{k}_{\mathrm{t}}$ " $\mathrm{uv}$.

\subsection{Determination of $U V$ factor, $T_{B}(U V)$}

The database defined in section 2.1 was used to determine the UV (290295-385 nm) Band Factor. The instants corresponding to air mass greater than 6.0 were eliminated as it was considered that these instants corresponded to solar altitudes of little interest. The cloudy instants according $\mathrm{k}_{\mathrm{t}}$ ' criterion were also eliminated and then the resulting database contained 30,300 instants.

Applying eq. (4), we will be able to determine the values of the Band Factor, $T_{B}(U V)$, having previously obtained direct normal irradiance measurements, $\mathrm{I}_{\mathrm{n}}$, of the band by the EM described in Section 3.1, and also applying eq. (6) to determine the input parameter $\delta_{\mathrm{CDA}}(\mathrm{UV})$.

In all clear instants, it is observed that independently of $m_{r}$, the UV Band Factor is $99 \%$ below 1.4, which is considered a maximum threshold value $\mathrm{T}_{\mathrm{Bmax}}=1.4$ for Valencia (Spain). This value will be applied to the determination, in Valencia, of the $\mathrm{k}_{\mathrm{t}}{ }^{\prime}$ ' $\mathrm{uv}$ index.

\subsection{Determination and Validation of the new clearness index, $k_{t}{ }^{\prime \prime} u v$}

$\mathrm{k}_{\mathrm{t}}$ "' $\mathrm{uv}$ has been determined in Valencia (Spain) for the period 1998-2004 and resulting in a total of 35,895 values for all conditions of clear or cloudy sky, once the measurements were removed for a mass of air greater than 6 . The values of $\mathrm{k}_{\mathrm{t}}$ ', $\mathrm{uv}$ have been correlated with their corresponding $\mathrm{k}_{\mathrm{t}}$ '. The graphic representation is shown in Figure 2, where the centerlines correspond to the fitting curve and its $95 \%$ confidence level interval, while the 2 farthest curves show the prediction interval for the same level of confidence. The setting equation, with a $\mathrm{R}^{2}$ of 0.85 , fits the expression

$k_{t}{ }^{\prime \prime}=1.505 k_{t}{ }^{\prime 0.741}$

We observenote in this correlation that the instantseiremmstances of $\mathrm{k}_{t}^{\prime \prime}{ }_{\mathrm{uv}}>1.1$ correspond toin which $\mathrm{k}_{\mathrm{t}}{ }^{\prime}>$ 0.7 , which corresponds to $k_{t}^{\prime \prime}, w z>1.1$. If $k_{t}{ }^{\prime}>0.7$ is considered a condition for clear skies from broadband measurements. Therefore, hen UV band - it can be established, for UV band, that measurements in which $\mathrm{k}_{\mathrm{t}}$ "' Uv is greater than 1.1 correspond to cloudless skies.

Thus $\mathrm{k}_{\mathrm{t}}{ }^{\prime} \mathrm{UV}_{\mathrm{V}}>1.1$ can be taken as a new criterion of cloudless conditions for the band, hereafter referred to as a band clearness criterion (BCC), to be applied only when UV band irradiance is available.

From measurements of years 1996 and 1997, all instants corresponding to cloudless and cloudy conditions was classified applying the both broadband criteria ( $\mathrm{k}_{\mathrm{t}}$ criterion and GDC), and simultaneously the new band criteria establish here, BCC. The results were compared and showed in table 4.

The mentioned database of the years 1996 and 1997 contained irradiance measurements from 11,383 instants, of which 7,272 were found cloudless according to $\mathrm{k}_{\mathrm{t}}$ criterion, 7,331 according to GDC, and 7,471 according to BCC. 
The cloudless instants obtained applying the $\mathrm{k}_{\mathrm{t}}$ criterion and cloudy for BCC were 347; and the cloudless instants under the new criterion and considered cloudy by the $\mathrm{k}_{\mathrm{t}}$ criterion were 546 . We can observe that the disagreement between the two criteria was 893 out of 11,383 instants and it represents $7.8 \%$.

Performing the same procedure between the GDC and BCC criteria, the obtained values are shown in Table 4, where it can be observed that BCC disagrees with GDC in 1,156 instants or $10.2 \%$.

\section{Table 4}

Disagreement instants in the application of the three criteria as shown by pairwise comparisons. The criteria in columns and rows are applied to select cloudy and cloudless conditions respectively.

\begin{tabular}{llll}
\hline \multicolumn{1}{c}{ Clouddess } & $\mathbf{k}_{\mathbf{t}}{ }_{\text {t }}$ criterion & GDC & BCC \\
\hline $\mathbf{k}_{\text {t }}$ criterion & - & 468 & 546 \\
GDC & 409 & - & 648 \\
BCC & 347 & 508 & - \\
\hline
\end{tabular}

To guarantee a greater accuracy in selecting cloudless instants, we have simultaneously applied both broadband criteria and then we have made a comparison with the cloudless selection when applying BCC. While 288 instants were clear according BCC, they remain cloudy according to the other two criteria. Otherwise, 298 instants were clear according to the two broadband criteria and cloudy when applying BCC. A disagreement was shown for 586 out of 11,383 instants, which represents an error likelihoodprobability_of $5.1 \%$. Therefore, we can state that the likelihood probability of BCC making the same selection of cloudless skies, at the same time as the two broadband criteria, is $94.8 \%$.

\section{Conclusions}

A new $\mathrm{k}_{\mathrm{t}}$ ' index, that we term the 'zenith angle independent clearness index' for a given band, expresses the ratio of the experimental direct normal irradiance over the minimum direct normal irradiance in cloudless skies. This index can be used as a classifier criterion, BCC, of cloudless sky conditions when only the UV band measurements are available.

$\underline{\text { BCC has been compared with two broadband classification methods from the literature, referred here as ' } \mathrm{k}}$.' criterion' and GDC. The selection of clear instants with BCC agrees 92.2\% with ' $\mathrm{k}_{t}^{\prime}$ ' criterion', and 89.8\% with GDC. Finally, the set of clear instants selected by BCC was compared with that selected by applying

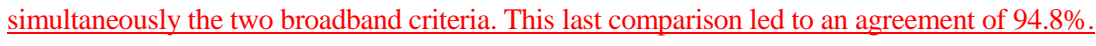


This criterion has been compared with two broadband classification methods given in the literature, namely $k_{\mathrm{t}}$ '- criterion and GDG. The selection of clear instants with BCC agrees $92.2 \%$ with the $k_{\mathrm{t}}$ '- criterion and $89.8 \%$ with GDG. And finally, comparing the BCC selection of clear instants with the selection made with the other two criteria applied simultaneously, leads to an agreement of $94.8 \%$.

Since the determination of BCC requires band direct normal irradiance data, we used the experimental database of the described measurement campaign to validate the EM (which had already been validated in the literature for the other spectral bands), and this way to be able to apply it to obtain a direct normal irradiance of the UV band from UV global horizontal.

We can conclude that band clearness criterion, BCC, could be of great usefulness for cloud screeningin eliminating cloudy instants. The new index, $\mathrm{k}_{\mathrm{t}}{ }^{\prime}$ ' $\mathrm{uv}$, in which this criterion is based, may be an interesting tool to manage UV irradiance databases for an analysis of clear instants when broadband irradiance data are unavailable.

\section{Acknowledgements}

The authors would like to thank Dr. Javier Cañada, Professor of the Universitat Politècnica de València, for his cooperation in this study, who provided us with measurement data. Also, the authors want to express a warm tribute to him as he passed away recently after an intense life devoted to teaching and research.

The translation of this paper was funded by the Universitat Politècnica de València, Spain.

This work was supported by the Spanish Government through MEC grant MAT2006-02279, and was a part of the activities of the Grup d'Optoelectrónica i Semiconductors of the Universitat Politècnica de València, Spain. 


\section{References}

Alados-Arboledas, L., Olmo F.J., Alados I., Pérez M., 2000. Parametric models to estimate photosynthetically active radiation in Spain. Agricultural and Forest Meteorology 101,187-201.

Barth, J., Cadet J., Césarini J.P., Fitzpatrick T.B., McKinlay A., Mutzhas M., Pathak M., Peak M., Sliney D., Urbach F., 1999. TC 6-26 report: Standardization of the terms UV-A1, UV-A2 and UV-B, CIE 1341999, ISBN 3-900-734-94-1.

Batlles F.J., Olmo F.J., Alados-Arboledas L., 1995. On shadowband correction methods for diffuse irradiance measurements. Solar Energy 54 (2), 105-114.

Black, J.N., Bonython, C.W., Precott, J.A., 1954. Solar radiation and the duration of sunshine. Quart. J. Roy. Met. Soc. 80, 231-235.

Bo, H., Yuesi, W., Guangren, L., 2010. Properties of ultraviolet radiation and the relationship between ultraviolet radiation and aerosol optical depth in China. Atmospheric Research 98, 297-308.

Boata, R. St., Gravila, P., 2012. Functional fuzzy approach for forecasting daily global solar irradiation. Atmospheric Research 112, 79-88.

Boscà, J.V., Pinazo, J.M., Cañada, J., Ruiz, V., 1996. Angström’s Turbidity Coefficient in Seville, Spain in the Years 1990 and 1991. International Journal of Ambient Energy 17, 4, 171- 178.

Cañada, J., Pedrós, G., López, A., Boscà, J.V., 2000. Influences of the clearness index for the whole spectrum and of the relative optical air mass on UV solar irradiance for two locations in the Mediterranean area, Valencia and Córdoba. J. Geophys. Res. 106 (D4), 4759-4766.

Cañada, J., Pedrós, G., Boscà, J.V., 2003. Relationships between UV (0.290-0.385 ㅆm) and broad band solar radiation hourly values in Valencia and Córdoba, Spain. Energy 28, 199-217.

Collares-Pereira, M., Rabl, A., 1979. The average distribution of solar radiation correlations between diffuse and hemispherical and between daily and hourly insolation values. Solar Energy 22, 155-164.

Foyo-Moreno, I., Vida J., Alados-Arboledas L., 1999. A Simple All Weather Model to Estimate Ultraviolet Solar Radiation (290-385 nm). Journal of applied meteorology 38, 1020-1026.

Gueymard, C., 2003. SMARTS2 code, versión 2.9.2. User’s Manual , Solar Consulting Services Bailey CO. Available from http://rredc.nrel.gov/solar/models/SMARTS/smarts index.html. 
Gueymard, C., 2004. The sun's total and spectral irradiance for solar energy applications and solar radiation models. Solar Energy 76, 423-453.

Iqbal. M., 1983. An introduction to solar radiation. Toronto, Academic Press.

Jacovides, C.P., Kaltsounides, N.A., Flocas, H.A., Asimakopoulos, D.N., 2009. Spectral investigation of the diffuse-to-direct solar beam irradiances ratio (UV-VIS) in the urban Athens atmosphere. Meteorol. Atmos. Phys. 104, 199-211.

Jacovides, C.P., Boland, J., Rizou, D., Kaltsounides, N.A., Theoharatos, G.A., 2012. School students participation in monitoring solar radiation components: Preliminary results for UVB and UVA solar radiant fluxes. Ren. Energy 39, 367-374.

Kasten, F., 1980. A simple parameterization of the pyrheliometric formula for determining the Linke turbidity factor. Meteorol. Rdsch. 33, 124-127.

Kratzenberg, M.G., Beyer, H.G., Colle, S., Albertazzi, A., 2006. Uncertainty calculations in pyranometer measurements and application. ASME 2006 International Solar Energy Conference (ISEC2006), July 2006, Denver, Colorado, USA, paper num. ISEC2006-99168, pp. 689-698, http://

dx.doi.org/10.1115/ISEC2006-99168.

Kudish, A.I., Evseev, E.G., 2012. UVB irradiance and atmospheric optical depth at the Dead Sea basin, Israel: Measurements and modelling. Renewable Energy 48, 344-349.

Liu, B.H., Jordan, R.C., 1960. The interrelationship and characteristic distribution of direct, diffuse and total solar radiation. Solar Energy 4, 1-19.

Martínez-Lozano, J.A., Casanovas, A.J., Utrillas, M.P., 1994. Comparison of global ultraviolet (290-385 $\mathrm{nm}$ ) and global irradiation measured during the warm season in Valencia, Spain. Int. J. Climatol. 14, 93102.

Martínez-Lozano, J.A., Tena, F., Utrillas, M.P., 1999. Ratio of UV to global broad band irradiation in Valencia, Spain. Int. J. Climatol 19, 903-911.

Mehos, M.S., Pacheco, K.A., Link, H.E., 1992. Measurement and analysis of near ultraviolet solar radiation. In: Proceeding of ASME, International Solar Energy Conference, Mauni, Hawaii.

Molineaux, B., Ineichen, P., Delaunay, J.J., 1995. Direct luminous efficacy and atmospheric turbidity: improving model performance. Solar Energy 55, 125-137. 
Ogunjobi, K.O., Kim, Y.J., 2004. Ultraviolet (0.280-0.400 Am) and broadband solar hourly radiation at Kwangju, South Korea: analysis of their correlation with aerosol optical depth and clearness index. Atmospheric Research 71, 193-214.

Parisi, A.V., Kimlin, M.G., 1999. Horizontal and sun-normal spectral biologically effective ultraviolet Irradiances. J. Photochem. Photobiol. B: Biol. 53, 70-74.

Parisi, A.V., Kimlin M.G., Wong J.C.F., Wilson M., 2000. Diffuse components of solar ultraviolet radiation in tree shade. J. Photoch. Photobiol. 54 B, 116-120.

Pérez, R., Ineichen P., Seals R., Zelenka A., 1990. Making full use of the clearness index for parameterising hourly insolation conditions. Solar Energy 45, 111-114.

Riordan, C.J., Hulstrom, R.L., Myers, D.R., 1990. Influences of atmospheric conditions and air mass on the ratio of ultraviolet to total solar radiation. Technical Report SERI/TP-215-3895, Golden, Colorado, USA, NREL.

Serrano, M.A., 2007. Estudio de Irradiancia de Bandas del Espectro Solar. Factores de Banda para la Caracterización de Condiciones Atmosféricas en Valencia. Doctoral Thesis. Polytechnic University of Valencia (Spain). July 2007. http://hdl.handle.net/10251/27595.

Serrano, M.A., Boscà, J.V., Cañada, J., 2008. The determination of a Band Factor to express irradiance of UV and PAR wavelength ranges in a clean and dry atmosphere at Valencia (Spain). International Journal of Ambient Energy 29 (4), 171-180.

Serrano, M.A., Boscà, J.V., 2011. Validation of a method to estimate direct normal irradiance of UVA and PAR bands from global horizontal measurements for cloudless sky conditions in Valencia, Spain, by a measurement campaign. Theor Appl Climatol 103, 95-101.

Turnbull, D.J., Parisi, A.V., Kimlin, M.G., 2005. Vitamin D effective ultraviolet wavelengths due to scattering in shade. J. Steroid. Biochem Mol. Biol. 96, 431-436. 


\section{FIGURE CAPTIONS}

Fig. 1. Comparison between direct normal irradiance provided by EM and the real direct normal irradiance of the UV band in Valencia, Spain.

Fig. 2. Scatter plot of the UV band clearness index ( $\left.\mathrm{k}_{\mathrm{t}}\right)$ against the full band clearness index ( $\left.\mathrm{k}_{\mathrm{t}}^{\prime}\right)$. The centerlines correspond to the fitting curve and its $95 \%$ confidence level interval, while the 2 lines farthest

show the prediction interval to a confidence level of 95\%.

Con formato: Subíndice

Con formato: Subíndice 


\section{Glossary}

$\mathrm{k}_{\mathrm{t}} \quad$ clearness index: defined as the ratio of global irradiance at the Earth's surface over extraterrestrial irradiance, defined by Black et al. 1954.

$\mathrm{k}_{\mathrm{tUV}} \quad$ clearness index: for UV measurements.

$\mathrm{k}_{\mathrm{t}} \quad$ zenith angle independent clearness index, defined by Pérez et al. (1990).

$\mathrm{k}_{\mathrm{t}}$ criterion cloudless sky conditions for values of $\mathrm{k}_{\mathrm{t}}$ up to 0.7 (Molineaux et al. 1995).

$\delta_{\mathrm{CDA}} \quad$ the optical depth of a clean and dry atmosphere.

EM estimation method: a method to estimate direct normal irradiance of spectral bands from global horizontal band measurements for cloudless sky conditions in Valencia.

$\mathrm{T}_{\mathrm{B}}(\mathrm{UV}) \quad$ UV Band Factor: $T_{B}(U V)=\frac{1}{m_{r} \delta_{C D A}(U V)} \ln \left[\frac{E_{0} I_{0}(U V)}{I_{n}(U V)}\right]$, where $\mathrm{I}_{0}(\mathrm{UV})$ is the extraterrestrial solar constant between the wavelengths 290295 to $385 \mathrm{~nm}$ obtained from the spectrum of Gueymard (2004) with a value of $83.80280 .985 \mathrm{~W} / \mathrm{m}^{2}, \mathrm{I}_{\mathrm{n}}(\mathrm{UV})$ direct normal irradiance of the UV band, $\mathrm{E}_{0}$ eccentricity of earth's orbit.

$\mathrm{k}_{\mathrm{t}}$ ” $\quad$ zenith angle independent band clearness index: the ratio of direct normal experimental irradiance over the minimum direct normal irradiance in cloudless conditions, for a spectral band.

BCC band clearness criterion: based on $\mathrm{k}_{\mathrm{t}}{ }^{\prime \prime} \mathrm{uv}$. When $\mathrm{k}_{\mathrm{t}}{ }^{\prime \prime} \mathrm{uv}>1.1$ can be taken as a new criterion of cloudless conditions.

GDC global and diffuse criterion: established threshold values of direct normal and horizontal diffuse irradiance by applying the broadband Iqbal C Model (Iqbal 1983) in conditions of high turbidity and water vapour content in the atmosphere, and then comparing with the current global and diffuse horizontal irradiance. 
María Antonia Serrano received her Ph.D. in 2007 from the Universitat Politècnica de València, Spain, where she is Associate Professor. She is member of the Instituto de Ingeniería Energética, and of the Valencia Solar Radiation Group, considered Valencia Excellence Group through Project Prometheus 2010. Her research focuses on solar UV radiation. Regarding UV modelling she has published 2 articles, and other six papers regarding erythematic irradiance all, except one, in journals included in JCR and as the corresponding author. Nowadays she participates as a researcher in the research project CGL201015931 supported by the Spanish Ministry of Science and Innovation.

José V. Boscà received the M. Sc. degree in physics from the University of Valencia, and the Ph. D. degree in physics from the Polytechnic University of Valencia, Spain, where he continued as a professor. His research was devoted to the solar radiation field particularly in order to contribute to improve parameterised models of irradiative transfer in the atmosphere for the broad band range and UV band. He is retired since October, 2010, and currently he only makes some occasional works about subjects that he expertise. 